\title{
A Survey of New Methods for Production of Some Radionuclides, at Laboratory Scale, through Secondary Reactions in Nuclear Reactors
}

\author{
Isaac M. Cohen ${ }^{1,2}$, Sandra Siri ${ }^{3}$, María C. Fornaciari Iljadica ${ }^{3}$ \\ ${ }^{1}$ Facultad Regional Avellaneda, Universidad Tecnológica Nacional, Avellaneda, Argentina \\ ${ }^{2}$ Facultad Regional Buenos Aires, Universidad Tecnológica Nacional, Buenos Aires, Argentina \\ ${ }^{3}$ Centro Atómico Ezeiza, Comisión Nacional de Energía Atómica, Ezeiza, Argentina \\ Email: icohen@fra.utn.edu.ar, mcohen@frba.utn.edu.ar, ssiri@cae.cnea.gov.ar, iljadica@cae.cnea.gov.ar
}

Received 9 March 2014; revised 9 April 2014; accepted 30 April 2014

Copyright (C) 2014 by authors and Scientific Research Publishing Inc.

This work is licensed under the Creative Commons Attribution International License (CC BY).

http://creativecommons.org/licenses/by/4.0/

c) (i) 0pen Access

\section{Abstract}

The studies performed in the frame of a project destined for the search of new $(t, n)$ and $(p, n)$ reactions of interest in nuclear reactors are described. Experimental evidences of the observations of the reactions: ${ }^{46} \mathrm{Ti}(\mathrm{t}, \mathrm{n}){ }^{48} \mathrm{~V},{ }^{48} \mathrm{Ti}(\mathrm{p}, \mathrm{n})^{48} \mathrm{~V},{ }^{52} \mathrm{Cr}(\mathrm{t}, \mathrm{n}){ }^{54} \mathrm{Mn},{ }^{56} \mathrm{Fe}(\mathrm{p}, \mathrm{n}){ }^{56} \mathrm{Co},{ }^{72} \mathrm{Ge}(\mathrm{t}, \mathrm{n}){ }^{74} \mathrm{As}$ and ${ }^{74} \mathrm{Ge}(\mathrm{p}, \mathrm{n}){ }^{74} \mathrm{As}$, are presented. Additional data on some secondary reactions, already characterised for the production of ${ }^{7} \mathrm{Be},{ }^{56} \mathrm{Co},{ }^{58} \mathrm{Co},{ }^{65} \mathrm{Zn}$ and ${ }^{88} \mathrm{Y}$, were also obtained. The significance of these data is discussed.

\section{Keywords}

Nuclear Reactions, Nuclear Reactors, Tritons, Recoil Protons

\section{Introduction}

Among other aspects, nuclear chemistry is linked with radiochemistry, as the branch of chemistry related to the study of the behaviour and the properties of radioactive materials, through the search of methods for production of many radionuclides of interest. Thus, the wide field of the applications of radioactive tracers rests on the availability of suitable radioisotopes for most of the elements.

Notably, nuclear reactors are the most used tool for radionuclide production. The amplitude of the reactor neutron spectrum, in terms of the energies of the neutrons, allows the generation of both capture and threshold 
reactions; among the latter, $(n, p)$ and $(n, \alpha)$ reactions lead to non-carrier added activities, well suited for the synthesis of tracers. Second order reactions, i.e. direct double neutron capture or neutron capture on a product of the decay of a primary neutron-induced reaction, are far less frequent and exceptionally employed. One of the few applications is the development of a ${ }^{188} \mathrm{~W}_{-}{ }^{188} \mathrm{Re}$ generator from the sequence: ${ }^{186} \mathrm{~W}(\mathrm{n}, \gamma){ }^{187} \mathrm{~W}(\mathrm{n}, \gamma){ }^{188} \mathrm{~W}(\beta){ }^{188} \mathrm{Re}$ [1].

Charged particles originated from a primary interaction of neutrons can also induce secondary reactions. Two different mechanisms were studied in the past, mostly connected with research purposes: a) reactions induced by tritons, produced through $(\mathrm{n}, \alpha)$ reaction on one of the stable isotopes of lithium, ${ }^{6} \mathrm{Li}$; b) reactions induced by recoil protons, resulted from the interaction of neutrons with hydrogen containing compounds (under similar principles, deuterium compounds were also used, in a very restricted extent, for the production of secondary reactions with recoil deuterons).

Tritons are produced in nuclear reactors by the reaction: ${ }^{6} \mathrm{Li}(\mathrm{n}, \alpha)^{3} \mathrm{H}$, which have thermal cross-section equal to $950 \mathrm{~b}$. They can in turn induce new reactions, $(\mathrm{t}, \mathrm{n})$ and $(\mathrm{t}, \mathrm{p})$ ones being the most probable. As a rule, these reactions are strongly exoergic, so that the only energetic restriction is the penetrability of the Coulomb barrier of the target nucleus. Taking into account the low energy of the tritons yielded by the $(\mathrm{n}, \alpha)$ reaction on ${ }^{6} \mathrm{Li}$ (approximately $2.74 \mathrm{MeV}$ ) most of the reactions investigated were connected to light elements. Examples of triton induced reactions in nuclear reactors are: ${ }^{10} \mathrm{~B}(\mathrm{t}, 2 \mathrm{n}){ }^{11} \mathrm{C}[2] ;{ }^{15} \mathrm{~N}(\mathrm{t}, \mathrm{p}){ }^{17} \mathrm{~N},{ }^{18} \mathrm{O}(\mathrm{t}, \mathrm{n}){ }^{20} \mathrm{~F}$ and ${ }^{18} \mathrm{O}(\mathrm{t}, \alpha){ }^{17} \mathrm{~N}[3] ;{ }^{16} \mathrm{O}(\mathrm{t}, \mathrm{n}){ }^{18} \mathrm{~F}$ and ${ }^{32} \mathrm{~S}(\mathrm{t}, \mathrm{n}){ }^{34 \mathrm{~m}} \mathrm{Cl}[4] ;{ }^{27} \mathrm{Al}(\mathrm{t}, \mathrm{p})^{29} \mathrm{Al}$ and ${ }^{26} \mathrm{Mg}(\mathrm{t}, \mathrm{p})^{28} \mathrm{Mg}$ [5]; ${ }^{20} \mathrm{Ne}(\mathrm{t}, \mathrm{n}){ }^{22} \mathrm{Na}$ [6]. Some practical applications of these reactions were published: production of ${ }^{26} \mathrm{Mg}$ [7] and ${ }^{18} \mathrm{~F}$ [8] with acceptable yields, for use as tracers; determination of lithium by activation analysis though the ${ }^{32} \mathrm{~S}(\mathrm{t}, \mathrm{n}){ }^{34 \mathrm{~m}} \mathrm{Cl}$ reaction [9]; determination of oxygen by the ${ }^{16} \mathrm{O}(\mathrm{t}, \mathrm{n}){ }^{18} \mathrm{~F}$ reaction [10]-[11].

The energy lost by a neutron of energy $E$ that interacts with a nucleus of atomic mass $A$ is $2 \mathrm{EA} /(\mathrm{A}+1)^{2}$. Thus, the recoil protons in a nuclear reactor have an average energy near half of the primary energy of the neutrons. Since the neutron spectrum in a core of the reactor comprises neutrons with maximum energies of about 20 $\mathrm{MeV}$, it is possible to predict that a fraction of the protons originated from collisions can penetrate the Coulomb barrier of many target elements and induce nuclear reactions. Under this initial outline, it is necessary to consider that, taking as reference a fission spectrum, the number of neutrons decreases from the maximum of the distribution, located at approximately $1 \mathrm{MeV}$. In addition, the scattering cross-section also diminishes with increasing energy of the neutrons, going from approximately $4.2 \mathrm{~b}$ at $1 \mathrm{MeV}$ to $0.5 \mathrm{~b}$ at $20 \mathrm{MeV}$ [12]. Therefore, the possibility of producing significant activities through reactions with recoil protons will be gradually smaller for growing atomic number of the targets, which implies higher Coulomb barriers. In practice, it is very difficult to conceive the production of reactions having thresholds $>10 \mathrm{MeV}$.

Among the reactions induced with protons, usually endoergic, the most probable are (p,n), although some other have been reported, especially in light nucleus.

The literature about reactions induced by recoil protons in nuclear reactors is relatively scarce. The first works, developed at the decade of the sixties, were related to the discovery of the possible reactions. Thus, Roy et al. [13] proposed in 1960 three methods for ${ }^{7} \mathrm{Be}$ production, using protons and deuterons as bombarding particles, by the reactions: ${ }^{10} \mathrm{~B}(\mathrm{p}, \alpha)^{7} \mathrm{Be},{ }^{7} \mathrm{Li}(\mathrm{p}, \mathrm{n})^{7} \mathrm{Be}$, and ${ }^{6} \mathrm{Li}(\mathrm{d}, \mathrm{n})^{7} \mathrm{Be}$; in the same year, Glickstein and Winter reported the reactions: ${ }^{11} \mathrm{~B}(\mathrm{p}, \mathrm{n}){ }^{11} \mathrm{C},{ }^{13} \mathrm{C}(\mathrm{p}, \mathrm{n}){ }^{13} \mathrm{~N}$, and ${ }^{18} \mathrm{O}(\mathrm{p}, \mathrm{n}){ }^{18} \mathrm{~F}$ [14]. Afterwards, Levin et al. obtained positive results investigating the ${ }^{65} \mathrm{Cu}(\mathrm{p}, \mathrm{n}){ }^{65} \mathrm{Zn}$ and ${ }^{88} \mathrm{Sr}(\mathrm{p}, \mathrm{n}){ }^{88} \mathrm{Y}$ reactions [15]. The reaction ${ }^{18} \mathrm{O}(\mathrm{p}, \mathrm{n}){ }^{18} \mathrm{~F}$ was used to determine the isotopic abundance of ${ }^{18} \mathrm{O}$ by activation analysis [16].

In connection with the disposal of nuclear waste after decommissioning of light water nuclear reactors, the activation of structural materials by recoil protons were studied [17]. A list of radioactive nuclides of interest formed by these reactions was elaborated and their activities were calculated.

The facts described in the above paragraphs allow observing that the majority of the research on triton or proton induced reactions in nuclear reactors were developed decades ago and also that few applications have been encountered for most of them. Such situation could lead to the conclusion that these fields are practically exhausted, which, in opinion of the authors, is wrong. Table 1 and Table 2 respectively show lists of reactions induced by tritons or protons in nuclear reactors that either have been or could be employed to obtain significant activities of several radionuclides. Since an analysis based on a realistic approach is intended, these tables are restricted to $(t, n)$ and $(p, n)$ reactions; the contributions of the present authors have been purposely excluded as references of the lists and will be described in the next sections.

It can be seen that $(\mathrm{t}, \mathrm{n})$ and $(\mathrm{p}, \mathrm{n})$ reactions are the only possibility of production of many radionuclides in a 
Table 1. Some practicable $(\mathrm{t}, \mathrm{n})$ reactions in nuclear reactors.

\begin{tabular}{cccc}
\hline Reaction & References & Neutron capture reaction leading to the product & Neutron threshold reactions leading to the product \\
\hline${ }^{16} \mathrm{O}(\mathrm{t}, \mathrm{n}){ }^{18} \mathrm{~F}$ & {$[4][7]$} & None & ${ }^{19} \mathrm{~F}(\mathrm{n}, 2 \mathrm{n}){ }^{18} \mathrm{~F}$ \\
$\left.{ }^{20} \mathrm{Ne}(\mathrm{t}, \mathrm{n})\right)^{22} \mathrm{Na}$ & {$[6]$} & None & ${ }^{23} \mathrm{Na}(\mathrm{n}, 2 \mathrm{n}){ }^{22} \mathrm{Na}$ \\
${ }^{46} \mathrm{Ti}(\mathrm{t}, \mathrm{n}){ }^{48} \mathrm{~V}$ & & None & None \\
${ }^{50} \mathrm{Cr}(\mathrm{t}, \mathrm{n}){ }^{52} \mathrm{Mn}$ & None & None \\
${ }^{52} \mathrm{Cr}(\mathrm{t}, \mathrm{n}){ }^{54} \mathrm{Mn}$ & & None & ${ }^{54} \mathrm{Fe}(\mathrm{n}, \mathrm{p}){ }^{54} \mathrm{Mn} ;{ }^{55} \mathrm{Mn}(\mathrm{n}, 2 \mathrm{n}){ }^{54} \mathrm{Mn}$ \\
${ }^{54} \mathrm{Fe}(\mathrm{t}, \mathrm{n}){ }^{56} \mathrm{Co}$ & {$[18]$} & None & None \\
${ }^{56} \mathrm{Fe}(\mathrm{t}, \mathrm{n}){ }^{58} \mathrm{Co}$ & {$[18]$} & None & ${ }^{58} \mathrm{Ni}(\mathrm{n}, \mathrm{p}){ }^{58} \mathrm{Co} ;{ }^{59} \mathrm{Co}(\mathrm{n}, 2 \mathrm{n}){ }^{58} \mathrm{Co}$ \\
${ }^{62} \mathrm{Ni}(\mathrm{t}, \mathrm{n}){ }^{64} \mathrm{Cu}$ & & ${ }^{64} \mathrm{Zn}(\mathrm{n}, \mathrm{p}){ }^{64} \mathrm{Cu} ;{ }^{65} \mathrm{Cu}(\mathrm{n}, 2 \mathrm{n}){ }^{64} \mathrm{Cu}$ \\
${ }^{63} \mathrm{Cu}(\mathrm{t}, \mathrm{n}){ }^{65} \mathrm{Zn}$ & ${ }^{64} \mathrm{Zn}(\mathrm{n}, \gamma){ }^{64} \mathrm{Cu} \mathrm{Zn}$ & ${ }^{66} \mathrm{Zn}(\mathrm{n}, 2 \mathrm{n}){ }^{65} \mathrm{Zn}$ \\
${ }^{64} \mathrm{Zn}(\mathrm{t}, \mathrm{n}){ }^{66} \mathrm{Ga}$ & None & $\mathrm{None}$ \\
${ }^{66} \mathrm{Zn}(\mathrm{t}, \mathrm{n}){ }^{68} \mathrm{Ga}$ & None & ${ }^{69} \mathrm{Ga}(\mathrm{n}, 2 \mathrm{n}){ }^{68} \mathrm{Ga}$ \\
${ }^{72} \mathrm{Ge}(\mathrm{t}, \mathrm{n}){ }^{74} \mathrm{As}$ & None & ${ }^{74} \mathrm{Se}(\mathrm{n}, \mathrm{p}){ }^{74} \mathrm{As} ;{ }^{74} \mathrm{As}(\mathrm{n}, 2 \mathrm{n}){ }^{74} \mathrm{As}$ \\
\hline
\end{tabular}

Table 2. Some practicable (p,n) reactions in nuclear reactors.

\begin{tabular}{|c|c|c|c|}
\hline Reaction & References & Neutron capture reaction leading to the product & Neutron threshold reactions leading to the product \\
\hline${ }^{7} \mathrm{Li}(\mathrm{p}, \mathrm{n})^{7} \mathrm{Be}$ & [13] [19] [20] & None & None \\
\hline${ }^{11} \mathrm{~B}(\mathrm{p}, \mathrm{n}){ }^{11} \mathrm{C}$ & [14] & None & ${ }^{12} \mathrm{C}(\mathrm{n}, 2 \mathrm{n}){ }^{11} \mathrm{C}$ \\
\hline${ }^{13} \mathrm{C}(\mathrm{p}, \mathrm{n}){ }^{13} \mathrm{~N}$ & [14] & None & ${ }^{14} \mathrm{~N}(\mathrm{n}, 2 \mathrm{n}){ }^{13} \mathrm{~N}$ \\
\hline${ }^{18} \mathrm{O}(\mathrm{p}, \mathrm{n}){ }^{18} \mathrm{~F}$ & [14] [20] & None & ${ }^{19} \mathrm{~F}(\mathrm{n}, 2 \mathrm{n}){ }^{18} \mathrm{~F}$ \\
\hline${ }^{48} \mathrm{Ti}(\mathrm{p}, \mathrm{n})^{48} \mathrm{~V}$ & & None & None \\
\hline${ }^{51} \mathrm{~V}(\mathrm{p}, \mathrm{n}){ }^{51} \mathrm{Cr}$ & {$[20]$} & ${ }^{52} \mathrm{Cr}(\mathrm{n}, \gamma)^{51} \mathrm{Cr}$ & ${ }^{54} \mathrm{Fe}(\mathrm{n}, \alpha){ }^{51} \mathrm{Cr} ;{ }^{52} \mathrm{Cr}(\mathrm{n}, 2 \mathrm{n}){ }^{51} \mathrm{Cr}$ \\
\hline${ }^{52} \mathrm{Cr}(\mathrm{p}, \mathrm{n}){ }^{52} \mathrm{Mn}$ & & None & None \\
\hline${ }^{56} \mathrm{Fe}(\mathrm{p}, \mathrm{n}){ }^{56} \mathrm{Co}$ & & None & None \\
\hline${ }^{65} \mathrm{Cu}(\mathrm{p}, \mathrm{n}){ }^{65} \mathrm{Zn}$ & {$[15][20]$} & ${ }^{64} \mathrm{Zn}(\mathrm{n}, \gamma){ }^{65} \mathrm{Zn}$ & ${ }^{66} \mathrm{Zn}(\mathrm{n}, 2 \mathrm{n}){ }^{65} \mathrm{Zn}$ \\
\hline${ }^{66} \mathrm{Zn}(\mathrm{p}, \mathrm{n}){ }^{66} \mathrm{Ga}$ & & None & None \\
\hline${ }^{67} \mathrm{Zn}(\mathrm{p}, \mathrm{n}){ }^{67} \mathrm{Ga}$ & & None & None \\
\hline${ }^{68} \mathrm{Zn}(\mathrm{p}, \mathrm{n}){ }^{68} \mathrm{Ga}$ & & None & ${ }^{69} \mathrm{Ga}(\mathrm{n}, 2 \mathrm{n}){ }^{68} \mathrm{Ga}$ \\
\hline${ }^{69} \mathrm{Ga}(\mathrm{p}, \mathrm{n}){ }^{69} \mathrm{Ge}$ & & None & ${ }^{70} \mathrm{Ge}(\mathrm{n}, 2 \mathrm{n}){ }^{69} \mathrm{Ge}$ \\
\hline${ }^{74} \mathrm{Ge}(\mathrm{p}, \mathrm{n}){ }^{74} \mathrm{As}$ & & None & ${ }^{74} \mathrm{Se}(\mathrm{n}, \mathrm{p}){ }^{74} \mathrm{As} ;{ }^{75} \mathrm{As}(\mathrm{n}, 2 \mathrm{n}){ }^{74} \mathrm{As}$ \\
\hline${ }^{75} \mathrm{As}(\mathrm{p}, \mathrm{n}){ }^{75} \mathrm{Se}$ & & ${ }^{74} \mathrm{Se}(\mathrm{n}, \gamma)^{75} \mathrm{Se}$ & ${ }^{76} \mathrm{Se}(\mathrm{n}, 2 \mathrm{n}){ }^{75} \mathrm{Se}$ \\
\hline${ }^{85} \mathrm{Rb}(\mathrm{p}, \mathrm{n}){ }^{85} \mathrm{Sr}$ & & ${ }^{84} \mathrm{Sr}(\mathrm{n}, \gamma){ }^{85} \mathrm{Sr}$ & ${ }^{86} \operatorname{Sr}(n, 2 n){ }^{85} \mathrm{Sr}$ \\
\hline${ }^{88} \operatorname{Sr}(p, n){ }^{88} Y$ & [15] & None & ${ }^{89} \mathrm{Y}(\mathrm{n}, 2 \mathrm{n}){ }^{88} \mathrm{Y}$ \\
\hline
\end{tabular}

nuclear reactor. The potential advantage is that the products are obtained with no carrier added, whereas those produced by $(n, \gamma)$ and $(n, 2 n)$ reactions are always accompanied with great quantities of stable carriers; only (n,p) and (n, $\alpha$ ), among the direct reactions induced by neutrons can compete (advantageously, most of the times) in that sense with the secondary reactions proposed; $(t, p)$ reactions have similar drawback to that mentioned for the 
$(n, \gamma)$ and $(n, 2 n)$ reactions, in connection with the presence of the stable carrier, and their interest is limited to some special cases, like the production of ${ }^{28} \mathrm{Mg}$, the only radionuclide of practical applications as tracer [7].

With respect to the yields of the proton induced reactions, the study of the reactions: ${ }^{7} \mathrm{Li}(\mathrm{p}, \mathrm{n}){ }^{7} \mathrm{Be},{ }^{18} \mathrm{O}(\mathrm{p}, \mathrm{n})^{18} \mathrm{~F}$, ${ }^{51} \mathrm{~V}(\mathrm{p}, \mathrm{n}){ }^{51} \mathrm{Cr}$ and ${ }^{65} \mathrm{Cu}(\mathrm{p}, \mathrm{n}){ }^{65} \mathrm{Zn}[20]$ demonstrated that they can be acceptably good.

In what follows, the studies carried out by the authors, in a frame of a project destined for the search of new $(\mathrm{t}, \mathrm{n})$ and $(\mathrm{p}, \mathrm{n})$ reactions of interest in nuclear reactors, will be described. Additional data on some reactions already characterized were also obtained. The ultimate purpose of the investigation was the definition of the possibility of preparation of radioactive tracers at laboratory scale or calibration sources.

\section{Experimental}

\subsection{Irradiations}

All the irradiations were carried out in the RA-3 reactor (Ezeiza Atomic Centre). The reactor is of the MTR pool type, with fuel elements of $20 \%$ enriched uranium. At nominal $10 \mathrm{MW}$ thermal power, the thermal flux of the most favourable positions reach $10^{14} \mathrm{n} \cdot \mathrm{cm}^{-2} \cdot \mathrm{s}^{-1}$.

Two irradiation positions were preferentially used for the different experiments, one of them predominantly thermal, with an intermediate thermal flux $\left(2.72 \times 10^{13} \mathrm{n} \cdot \mathrm{cm}^{-2} \cdot \mathrm{s}^{-1}\right)$ and other one characterised not only by a relatively high thermal flux $\left(3.43 \times 10^{13} \mathrm{n} \cdot \mathrm{cm}^{-2} \cdot \mathrm{s}^{-1}\right)$ but also by a significant fast flux $\left(1.04 \times 10^{13} \mathrm{n} \cdot \mathrm{cm}^{-2} \cdot \mathrm{s}^{-1}\right.$, as measured by the ${ }^{54} \mathrm{Fe}(\mathrm{n}, \mathrm{p}){ }^{54} \mathrm{Mn}$ reaction). Although the fast flux was not fully characterized, some preliminary experiments tend to demonstrate that it is similar to an undisturbed ${ }^{235} \mathrm{U}$ fission flux.

Spectrographically pure chemicals, whenever possible, or analytical grade reagents, were irradiated in masses smaller than $100 \mathrm{mg}$, sealed in quartz ampoules or wrapped in small aluminium envelopes, and placed in aluminium cans. Pure compounds having in their molecular composition both the precursor of the particles (lithium or hydrogen) and the target isotope, solutions (for proton-induced reactions) and intimate samples between precursor and target compounds were alternatively used. The irradiation times depended on the half-lives of the investigated radionuclides; calculations of the major activities that could be generated in each of the matrixes were also contemplated. These factors were considered, as well, in the definition of the decay times.

\subsection{Radiochemical Separations}

After irradiations, direct measurements were performed in many cases. When radiochemical separations became necessary, the purpose was to reach favourable conditions for identification and characterization of the product, rather than to accomplish a complete purification. The priority was, for all the experiments, to define the prospective possibilities of the use of the searched radionuclide.

\subsection{Measurement and Data Treatment}

Both the solutions resulting from the radiochemical separations or the irradiated powders were placed in measurement polyethylene vials of specific size and measured by high resolution gamma spectrometry in a system comprised of an EG\&G Ortec HPGe detector, having $1.97 \mathrm{keV}$ (FWHM) resolution for the $1332.5 \mathrm{keV}^{60} \mathrm{Co}$ peak, and associated electronics. The data treatment was carried out with the GammaVision Software [21]. For all peaks in a spectrum, the programme of this software analyses the information and generates as output data a list of background, net area, counting uncertainty, FWHM, and net count rate.

\section{Radionuclides and Reactions}

The list of radionuclides investigated and the corresponding reactions were:

\subsection{Beryllium-7}

This nuclide ( $\mathrm{t}_{1 / 2} 53.6 \mathrm{~d}$ ) is the only practicable radiotracer of beryllium; ${ }^{7} \mathrm{Be}$ sources is often employed in high resolution gamma spectrometry for the determination of energy calibration curves, because the gamma transition associated with its electron capture decay $(477.6 \mathrm{keV})$ corresponds to a region with scarce availability of adequate standards. As it was mentioned, the production of ${ }^{7} \mathrm{Be}$ by secondary reactions in nuclear reactors was described by Roy et al. [13]. On the basis of the irradiation of several lithium, boron and ${ }^{6} \mathrm{Li}$ enriched compounds for $5 \mathrm{~d}$ at a 
fast flux of $2.0 \times 10^{11} \mathrm{n} \cdot \mathrm{cm}^{-2} \cdot \mathrm{s}^{-1}$, they concluded that none of the reactions studied led to the production of large amounts of ${ }^{7} \mathrm{Be}$, and that the ${ }^{7} \mathrm{Li}(\mathrm{p}, \mathrm{n})^{7} \mathrm{Be}$ reaction on LiHO offered the most promising possibilities. At the authors' laboratory, different experiments destined to improve the yield of ${ }^{7}$ Be production were performed [22]. Samples of LiHO $\cdot \mathrm{H}_{2} \mathrm{O}$ powder and solutions of lithium carbonate were irradiated at a fast flux about $1.04 \times 10^{13} \mathrm{n} \cdot \mathrm{cm}^{-2} \cdot \mathrm{s}^{-1}$; ${ }^{7} \mathrm{Be}$ was easily identified by both direct measurement and after a radiochemical separation. Although ${ }^{7} \mathrm{Be}$ activity per unit of lithium mass obtained by irradiation of lithium in solution is significantly higher than that induced in solid lithium hydroxide (ratio $=4.3$ ) a production based on long irradiations could imply, as undesirable effect, the evolution of gaseous radiolysis products in the aqueous media. Therefore, the estimation of the prospective yield was calculated on the basis of the irradiation of powders.

For a routine of two irradiation cycles of five days, with two days elapsed in between, the activities obtained could reach $22.3 \mu$ g per gram of lithium (It should be taken into account that several tens of grams can be placed in an irradiation can).

\subsection{Vanadium-48}

Because of its relatively long half-life (15.97 d) and their gamma rays (983.5 keV and $1312.1 \mathrm{keV}$, among the most intense) ${ }^{48} \mathrm{~V}$ is the only practicable vanadium tracer; ${ }^{49} \mathrm{~V}$, in spite of its favourable half-life (330 d) is of very restricted potentiality, since no gamma emissions are associated to its decay. All the remaining radioisotopes are very short-lived.

${ }^{48} \mathrm{~V}$ is, typically, a cyclotron-produced radionuclide. Since no direct reactions exist in nuclear reactors leading to ${ }^{48} \mathrm{~V}$, the authors successfully attempted a novel method for its production by irradiation of $\mathrm{Li}_{2} \mathrm{TiO}_{3}$, through the sequence: ${ }^{6} \mathrm{Li}(\mathrm{n}, \alpha)^{3} \mathrm{H} ;{ }^{46} \mathrm{Ti}(\mathrm{t}, \mathrm{n})^{48} \mathrm{~V}$ [23] [24]; ${ }^{47} \mathrm{Ti}(\mathrm{t}, 2 \mathrm{n})^{48} \mathrm{~V}$ should also be considered, but with a priori less probability, due to its less favourable Q. Prospectively, the yield for a five days irradiation cycle is $4 \mu \mathrm{Ci}$ per gram of lithium titanate.

In view of the promising results obtained by tritons as bombarding particles, the possibilities of the ${ }^{48} \mathrm{Ti}(\mathrm{p}, \mathrm{n})^{48} \mathrm{~V}$ reaction with recoil protons were investigated. Samples of $\left(\mathrm{NH}_{4}\right)_{2} \mathrm{TiF}_{6}$ were irradiated for $24 \mathrm{~h}$ and measured after $20 \mathrm{~d}$. Although ${ }^{48} \mathrm{~V}$ was identified without the need of radiochemical separation, the yields were, somewhat surprisingly, considerably less that those obtained for tritons.

\subsection{Manganese-54}

The investigation was oriented to search for the possible existence of the ${ }^{52} \mathrm{Cr}(\mathrm{t}, \mathrm{n})^{54} \mathrm{Mn}$ reaction, taking into account that the precursor is the most abundant chromium isotope $(\theta=83.879 \%)$. Samples of $\mathrm{K}_{2} \mathrm{CrO}_{4}, \mathrm{~K}_{2} \mathrm{Cr}_{2} \mathrm{O}_{7}$, ${ }^{6} \mathrm{Li}_{2} \mathrm{CO}_{3}$, and mixtures: $\mathrm{K}_{2} \mathrm{Cr}_{2} \mathrm{O}_{7^{-}}{ }^{6} \mathrm{Li}_{2} \mathrm{CO}_{3}\left(1.4: 1\right.$ mass ratio) and $\mathrm{K}_{2} \mathrm{CrO}_{4}{ }^{-}{ }^{6} \mathrm{Li}_{2} \mathrm{CO}_{3}$ (1.8:1 mass ratio) were irradiated for $24 \mathrm{~h}$, in a predominantly thermal position. The samples were directly measured without chemical separation, after the decay of the ${ }^{51} \mathrm{Cr}$ formed by capture reaction (90 and 130 days).

Peaks at $834.8 \mathrm{keV}$ were observed in the samples of pure $\mathrm{K}_{2} \mathrm{CrO}_{4}$ and $\mathrm{K}_{2} \mathrm{Cr}_{2} \mathrm{O}_{7}$, attributable to iron impurities, which led to the formation of ${ }^{54} \mathrm{Mn}$ through (n,p) reaction on ${ }^{54} \mathrm{Fe}$, whereas ${ }^{6} \mathrm{Li}_{2} \mathrm{CO}_{3}$ showed a clean spectrum. The presence of ${ }^{54} \mathrm{Mn}$ was also confirmed in the $\mathrm{K}_{2} \mathrm{Cr}_{2} \mathrm{O}_{7}{ }^{-}{ }^{6} \mathrm{Li}_{2} \mathrm{CO}_{3}$ and $\mathrm{K}_{2} \mathrm{CrO}_{4}{ }^{6}{ }^{6} \mathrm{Li}_{2} \mathrm{CO}_{3}$ mixtures; since the activity per gram of the compounds was higher in the mixtures by a factor approximately equal to 5 , the conclusion was that the $(t, n)$ reaction had effectively taken place. However, the low yields obtained do not allow envisaging future applications.

\subsection{Cobalt-56, Cobalt-57, Cobalt-58 and Cobalt-60}

All these radionuclides are long-lived gamma emitters, well suited for their use as tracers (half-lives: $77.26 \mathrm{~d}$; $271.79 \mathrm{~d} ; 70.86 \mathrm{~d}$ and $5.27 \mathrm{y}$ ). Their gamma transitions differ significantly with respect to their energies, ranging from low-energies $\left({ }^{57} \mathrm{Co}, 122.1 \mathrm{keV}, 136.5 \mathrm{keV}\right)$; medium energies $\left({ }^{58} \mathrm{Co}, 810.8 \mathrm{keV}\right)$; high energies $\left({ }^{60} \mathrm{Co}, 1173.2\right.$ $\mathrm{keV}, 1332.5 \mathrm{kev})$; medium and high energies $\left({ }^{56} \mathrm{Co}, 846.8 \mathrm{keV}, 977.4 \mathrm{keV}, 1037.8 \mathrm{keV}, 1175.1 \mathrm{keV}, 1238.3 \mathrm{keV}\right.$, 1360.2 keV, $1771.3 \mathrm{keV}, 1810.7 \mathrm{keV}, 1963.7 \mathrm{keV}, 2015.2 \mathrm{keV}, 2034.8 \mathrm{keV}, 2113.1 \mathrm{keV}, 2212.9 \mathrm{keV}, 2598.4 \mathrm{keV}$, $3009.6 \mathrm{keV}, 3201.9 \mathrm{keV}, 3228.8 \mathrm{keV}, 3253.4 \mathrm{keV}, 3273.0 \mathrm{keV}, 3451.1 \mathrm{keV})$. Since all these energies have been precisely measured, they can be used as calibration standard; ${ }^{56} \mathrm{Co}$ constitutes a special case, because it is the only long-lived radionuclide, in condition of being employed as calibration standard, which shows such variety of transitions with very high energies. 
The production of both ${ }^{56} \mathrm{Co}$ and ${ }^{58} \mathrm{Co}$ by $(\mathrm{t}, \mathrm{n})$ reactions in a nuclear reactor has been already reported [18], in the first case making use of ${ }^{54} \mathrm{Fe}$ enriched targets. At the authors' laboratory, an investigation was performed [25] with the twofold objective of a): to verify if all the potential reactions induced with tritons on iron targets, i.e. ${ }^{54} \mathrm{Fe}(\mathrm{t}, \mathrm{n}){ }^{56} \mathrm{Co},{ }^{56} \mathrm{Fe}(\mathrm{t}, \mathrm{n}){ }^{58} \mathrm{Co}$ and ${ }^{58} \mathrm{Fe}(\mathrm{t}, \mathrm{n}){ }^{60} \mathrm{Co}$, could be produced in samples of natural isotopic composition, and b): to characterise new $(p, n)$ reactions, so far not studied, induced on iron by recoil protons; specifically, these reactions were: ${ }^{56} \mathrm{Fe}(\mathrm{p}, \mathrm{n}){ }^{56} \mathrm{Co},{ }^{57} \mathrm{Fe}(\mathrm{p}, \mathrm{n}){ }^{57} \mathrm{Co}$ and ${ }^{58} \mathrm{Fe}(\mathrm{p}, \mathrm{n}){ }^{58} \mathrm{Co}$.

Intimate mixtures: $\mathrm{Fe}$ (powder) ${ }^{6} \mathrm{Li}_{2} \mathrm{CO}_{3}(1: 2$ mass ratio) and $\mathrm{Fe}$ (powder)- $\mathrm{LiHO}$ (1:3 mass ratio) were irradiated for $12 \mathrm{~h}$ and $24 \mathrm{~h}$, respectively, in a position having $3.4 \times 10^{13} \mathrm{n} \cdot \mathrm{cm}^{-2} \cdot \mathrm{s}^{-1}$ thermal flux and $1.0 \times 10^{13} \mathrm{n} \cdot \mathrm{cm}^{-2} \cdot \mathrm{s}^{-1}$ fast flux. A simple method, based on the use of strong anionic resin in hydrochloric medium, was developed in order to separate the cobalt radioisotopes from the major activities generated on the iron matrix trough $(\mathrm{n}, \gamma)$ and $(\mathrm{n}, \mathrm{p})$ reactions, i.e. ${ }^{59} \mathrm{Fe}$ and ${ }^{54} \mathrm{Mn}$.

Traces of ${ }^{60} \mathrm{Co}$, probably due to cobalt impurities in the matrixes, were observed in the gamma spectra of the irradiated samples. The only significant activities detected correspond to ${ }^{58} \mathrm{Co}$ and ${ }^{56} \mathrm{Co}$, in the mixtures irradiated with tritons and protons, respectively. These results seem to reflect the influence of the isotopic abundance of the precursors of the searched reactions: ${ }^{54} \mathrm{Fe}, 5.8 \% ;{ }^{56} \mathrm{Fe}, 91.72 \% ;{ }^{57} \mathrm{Fe}, 2.2 \% ;{ }^{58} \mathrm{Fe}, 0.28 \%$. In both cases, the identified products were originated by ${ }^{56} \mathrm{Fe}$, the most abundant iron isotope. The calculated yields were $1 \mu \mathrm{Ci}$ for ${ }^{58} \mathrm{Co}$ and $0.1 \mu \mathrm{Ci}$ for ${ }^{56} \mathrm{Co}$.

\subsection{Zinc-65}

The production of ${ }^{65} \mathrm{Zn}$ with good yields via recoil protons in a nuclear reactor has been already reported [20]. The experiments at the authors' laboratory dealt with the possibility of obtaining this radionuclide from the ${ }^{63} \mathrm{Cu}(\mathrm{t}, \mathrm{n}){ }^{65} \mathrm{Zn}$ reaction.

Samples of ${ }^{6} \mathrm{Li}_{2} \mathrm{CO}_{3}, \mathrm{CuO}$ and $\mathrm{CuO}-{ }^{6} \mathrm{Li}_{2} \mathrm{CO}_{3}$ intimate mixture (1:0.7 mass ratio) were irradiated for $12 \mathrm{~h}$ in a predominantly thermal position and in a less thermalized one. Different measurements were accomplished with decays between 24 and 50 days. Since small impurities of zinc are frequently found in many analytical chemicals, and considering that ${ }^{65} \mathrm{Zn}$ can be formed by neutron capture, its presence was checked both in the mixture that acted as target and also in the isolated compounds. The peak at $1115.5 \mathrm{keV}$ was identified in the mixture and also in the pure copper oxide. The statistical differences between counting rates do not permit to conclude that ${ }^{65} \mathrm{Zn}$ could have been produced by $(t, n)$ reaction.

\subsection{Arsenic-74}

Only ${ }^{73}$ As and ${ }^{74} \mathrm{As}$, among arsenic radioisotopes, have half-lives sufficiently high for their use as tracers in studies of long duration ( $\mathrm{t}_{1 / 2}: 80.3 \mathrm{~d}$ and $17.77 \mathrm{~d}$ ). Due to the fact that ${ }^{74} \mathrm{As}$ is a gamma emitter of medium energies (595.8 $\mathrm{keV}$ and $634.8 \mathrm{keV}$ ) it is probably more suitable for measurement, in comparison with ${ }^{73} \mathrm{As}$, which emits a low-energy gamma radiation $(53.4 \mathrm{keV})$.

The ways of ${ }^{74}$ As production in a nuclear reactor are the ${ }^{75} \mathrm{As}(\mathrm{n}, 2 \mathrm{n}){ }^{74} \mathrm{As}$ and ${ }^{74} \mathrm{Se}(\mathrm{n}, \mathrm{p}){ }^{74} \mathrm{As}$ reactions. The unavoidable low specific activity of the ${ }^{74} \mathrm{As}$ formed form the first reaction, due to the presence of the stable isotope, precludes its use as tracer. The (n,p) reaction on ${ }^{74} \mathrm{Se}$ allows radiochemical separation between ${ }^{74} \mathrm{As}$ and its precursor, making it possible to obtain better specific activities; the product must be separated from very high levels of ${ }^{75}$ Se activity generated by neutron capture. The experiments carried out at the authors' laboratory [26] [27] showed a ratio of activities: ${ }^{75} \mathrm{Se} /{ }^{74} \mathrm{As}$ equal to 5100 at the end of a $13 \mathrm{~h}$ irradiation in a less thermalized position of the RA-3 reactor. Since ${ }^{75} \mathrm{Se}$ is longer-lived ( $\mathrm{t}_{1 / 2}: 119.64 \mathrm{~d}$ ) than ${ }^{74} \mathrm{As}$, the situation worsens with the decay.

The authors have investigated the possibilities of producing ${ }^{74} \mathrm{As}$ in a nuclear reactor via ${ }^{72} \mathrm{Ge}(\mathrm{t}, \mathrm{n}){ }^{74} \mathrm{As}$ and ${ }^{74} \mathrm{Ge}(\mathrm{p}, \mathrm{n}){ }^{74} \mathrm{As}$. For the study of $(\mathrm{t}, \mathrm{n})$ reaction, several irradiations of samples of $\mathrm{GeO}_{2}$ and ${ }^{6} \mathrm{Li}_{2} \mathrm{CO}_{3}$ pure compounds and intimate mixtures: $\mathrm{GeO}_{2}-{ }^{6} \mathrm{Li}_{2} \mathrm{CO}_{3}$ (mass ratios between 1:1 and 1:1.15), weighing less than $100 \mathrm{mg}$, were performed for $12 \mathrm{~h}$ in both a predominantly thermal position and another one, less thermalized. Identical irradiations of $\mathrm{GeO}_{2}, \mathrm{NH}_{4} \mathrm{NO}_{3}$ and mixtures: $\mathrm{GeO}_{2}-\mathrm{NH}_{4} \mathrm{NO}_{3}$ (1:3 mass ratio) were accomplished for the (p,n) reaction.

All the samples were repeatedly measured after decays between 7 and 45 days. Peaks at $595.8 \mathrm{keV}$ and 634.8 $\mathrm{keV}$, reasonably attributable to ${ }^{74} \mathrm{As}$, were identified in the mixtures: $\mathrm{GeO}_{2}{ }^{6}{ }^{6} \mathrm{Li}_{2} \mathrm{CO}_{3}$ and $\mathrm{GeO}_{2}-\mathrm{NH}_{4} \mathrm{NO}_{3}$. The calculated yields were very similar, about $4 \mu$ g per gram of germanium. 


\subsection{Ytrium-88}

The interest in this radionuclide ( $\mathrm{t}_{1 / 2}: 106.6 \mathrm{~d}$ ) rest on its use as standard for calibration in energy, due to the gamma emissions of $898.0 \mathrm{keV}$ and, especially, $1836.1 \mathrm{keV}$. The production of ${ }^{88} \mathrm{Y}$ via recoil protons on strontium oxide targets have been reported several years ago [15]. The authors intended another way of production, on the basis of the reaction: ${ }^{86} \mathrm{Sr}(\mathrm{t}, \mathrm{n})^{88} \mathrm{Y}$.

Samples of $\mathrm{SrCl}_{2} \cdot 6 \mathrm{H}_{2} \mathrm{O}$, anhydrous $\mathrm{SrCl}_{2},{ }^{6} \mathrm{Li}_{2} \mathrm{CO}_{3}$ and intimate mixtures $\mathrm{SrCl}_{2}-{ }^{6} \mathrm{Li}_{2} \mathrm{CO}_{3}$ (mass ratio 1:1.6) were irradiated for $12 \mathrm{~h}$ in two different positions of the reactor. Several measurements were performed after 24 - 50 days decay. Whereas ${ }^{88} \mathrm{Y}$ was identified in the $\mathrm{SrCl}_{2} \cdot 6 \mathrm{H}_{2} \mathrm{O}$ samples, thus confirming the results of the literature [15], it was not detected in any other samples.

\section{General Discussion and Concluding Remarks}

As far as the authors know, the observation of the reactions: ${ }^{46} \mathrm{Ti}(\mathrm{t}, \mathrm{n}){ }^{48} \mathrm{~V},{ }^{48} \mathrm{Ti}(\mathrm{p}, \mathrm{n}){ }^{48} \mathrm{~V},{ }^{52} \mathrm{Cr}(\mathrm{t}, \mathrm{n}){ }^{54} \mathrm{Mn},{ }^{56} \mathrm{Fe}(\mathrm{p}, \mathrm{n}){ }^{56} \mathrm{Co}$, ${ }^{72} \mathrm{Ge}(\mathrm{t}, \mathrm{n}){ }^{74}$ As and ${ }^{74} \mathrm{Ge}(\mathrm{p}, \mathrm{n}){ }^{74}$ As in nuclear reactors had not been previously informed in the literature. Three of them lead to radionuclides $\left({ }^{48} \mathrm{~V}\right.$ and $\left.{ }^{56} \mathrm{Co}\right)$ that cannot be produced by direct reactions in nuclear reactors, and the reactions leading to ${ }^{74} \mathrm{As}$ can be reasonably options with respect to the $(n, p)$ and $(n, 2 n)$ reactions, taking into account the drawbacks already discussed in connection with these modes of production. On the other hand, although the demonstration of the triton induced production of ${ }^{54} \mathrm{Mn}$ contributes to enhance the knowledge about these reactions, no advantages were observed for its practical application, since this radionuclide is easily obtained with good yields by the ${ }^{54} \mathrm{Fe}(\mathrm{n}, \mathrm{p})^{54} \mathrm{Mn}$ reaction. Similar consideration can be formulated with respect to the production of ${ }^{58} \mathrm{Co}$ by $(\mathrm{t}, \mathrm{n})$ reaction on ${ }^{56} \mathrm{Fe}$, in comparison with the reaction: ${ }^{58} \mathrm{Ni}(\mathrm{n}, \mathrm{p}){ }^{58} \mathrm{Co}$.

Negative results were obtained in connection with other reactions investigated on iron, namely ${ }^{54} \mathrm{Fe}(\mathrm{t}, \mathrm{n}){ }^{56} \mathrm{Co}$, ${ }^{58} \mathrm{Fe}(\mathrm{t}, \mathrm{n}){ }^{60} \mathrm{Co},{ }^{57} \mathrm{Fe}(\mathrm{p}, \mathrm{n}){ }^{57} \mathrm{Co}$ and ${ }^{58} \mathrm{Fe}(\mathrm{p}, \mathrm{n}){ }^{58} \mathrm{Co}$, possibly due to the low isotopic abundances of the precursors.

In spite of the good yields reported for the production of ${ }^{65} \mathrm{Zn}$ through recoil protons [20] no significant results were obtained using tritons as the bombarding particles; the hypothetical activities produced are indistinguishable from those induced by neutron capture on the zinc impurities of the copper compound, which reveals a very low yield.

As it was mentioned above, the search for the ${ }^{86} \operatorname{Sr}(t, n){ }^{88} Y$ reaction failed; this fact leads to the question if the upper limit for the $(t, n)$ reactions in nuclear reactors has been already reached, considering the low energy of the tritons. It is worthwhile mentioning that the reaction: ${ }^{72} \mathrm{Ge}(\mathrm{t}, \mathrm{n}){ }^{74} \mathrm{As}$, reported in the present work, refers to a precursor having the highest atomic number so far known. Instead, the reasonably expectation is that new radionuclides, with higher $\mathrm{Z}$, can be obtained through reactions induced by recoil protons, and more work will be performed along these lines.

The results allow concluding that some radionuclides can be produced, at laboratory scale, with reasonably good yields; this is the case, for example, of ${ }^{7} \mathrm{Be}$ and ${ }^{48} \mathrm{~V}$. The yields for ${ }^{56} \mathrm{Co}$ and ${ }^{74} \mathrm{As}$ could improve by irradiation of the samples in positions of highest fluxes and with more favourable ratios of the precursor particle compounds to the target compounds. In connection with the proton-induced reactions, the hydrogenous compounds, because of their variety, open a rich field to future studies.

\section{References}

[1] Knapp Jr., F.F. (2001) Future Prospects for Medical Radionuclide Production in the High Flux Isotope Reactor (HFIR) at the Oak Ridge National Laboratory (ORNL). Annals of Nuclear Medicine Science, 14, 109-118.

[2] Roy, J.C. and Hawton, J.J. (1961) The $\mathrm{B}^{10}(\alpha, \mathrm{n}) \mathrm{N}^{13}$ and $\mathrm{B}^{10}(\mathrm{t}, 2 \mathrm{n}) \mathrm{C}^{11}$ Reactions in a Nuclear Reactor. Canadian Journal of Physics, 39, 1528-1534. http://dx.doi.org/10.1139/p61-183

[3] Sher, R. and Floyd, J.J. (1956) Triton-Induced Reactions. Physical Review, 102, 242. http://dx.doi.org/10.1103/PhysRev.102.242

[4] Knight, J.D., Novey, T.B., Cannon, C.V. and Turkevich, A. (1949) Activities from Tritium Bombardment in Neutron Irradiation of Lithium Salts: $(t, n)$ Reaction on Oxygen and Sulfur. Radiochemical Studies, The Fission Products, Book 3, McGraw-Hill, New York, 1916-1923.

[5] Iwersen, E., Koski, W.S. and Rasetti, F. (1953) Triton-Induced Activities in Magnesium and Aluminum. Physical Review, 91, 1229-1231. http://dx.doi.org/10.1103/PhysRev.91.1229

[6] Cook, L.G. and Shafer, K.D. (1954) The Production of ${ }^{22} \mathrm{Na}$ by $\left({ }^{3} \mathrm{H}, \mathrm{n}\right)$ Reaction in a Nuclear Reactor. Canadian Jour- 
nal of Chemistry, 32, 94-97. http://dx.doi.org/10.1139/v54-016

[7] Robson, J. and Sorby, P.J. (1974) The Preparation of Mg-28 by the Irradiation in HIFAR of Mixtures Containing Compounds of Li-6 and Mg-26. Australian Atomic Energy Commission Report AAEC-E310. Australian Atomic Energy Commission, Lucas Heights, Sidney.

[8] Wessels, B.W., Yusoff, W.R. and Ercegovic, D. (1985) Reactor Production of Anhydrous ${ }^{18}$ F Ion. Journal of Radioanalytical and Nuclear Chemistry, Articles, 92, 27-35. http://dx.doi.org/10.1007/BF02065387

[9] Cohen, I.M., Magnavacca, C. and Baró, G.B. (1987) Determination of Lithium by Reactor Activation Analysis Using the Reaction Chain: ${ }^{6} \mathrm{Li}(\mathrm{n}, \mathrm{t}){ }^{4} \mathrm{He} ;{ }^{32} \mathrm{~S}(\mathrm{t}, \mathrm{n}){ }^{34 \mathrm{~m}} \mathrm{Cl}$. Journal of Radioanalytical Chemistry, 112, 387-394. http://dx.doi.org/10.1007/BF02132371

[10] Absattarova, A., Kist, A.A. and Mukhammedov, S. (1988) Triton Activation in Oxygen Determination. Soviet Atomic Energy, 65, 934-936 (Translated from Atomnaya Énergiya, 65, 361-362).

[11] de Goeij, J.J.M. (2003) Triton Activation Analysis of Oxygen in a Nuclear Reactor. 6th International Conference on Methods and Applications of Radioanalytical Chemistry (MARC VI), Kailua-Kona, 7-11 April 2003, 136.

[12] Stewart, L. (1979) Hydrogen Scattering Cross Section, H(n,n)H. University of California, Los Alamos Scientific Laboratory Report LA-7899-MS, Informal Report. Los Alamos Scientific Laboratory, New Mexico, 1-15.

[13] Roy, J.C., Hawton, J.J. and Bresesti, M. (1960) On the Production of $\mathrm{Be}^{7}$ in the NRX Reactor by the $\mathrm{B}^{10}(\mathrm{p}, \alpha) \mathrm{Be}^{7}$, $\mathrm{Li}^{7}(\mathrm{p}, \mathrm{n}) \mathrm{Be}^{7}$, and $\mathrm{Li}^{6}(\mathrm{~d}, \mathrm{n}) \mathrm{Be}^{7}$ Reactions. Canadian Journal of Physics, 38, 1428-1435. http://dx.doi.org/10.1139/p60-148

[14] Glickstein, S.S. and Winter, R.G. (1960) Nuclear Reactions from Recoil Protons in a Reactor. Nuclear Instruments and Methods, 9, 226-228. http://dx.doi.org/10.1016/0029-554X(60)90105-1

[15] Levin, V.I., Malinin, A.B., Novoselov, V.S., Petrina, R.V. and Zav’yalova, L.V. (1968) Radioactive Isotopes from Recoil Protons in a Reactor. Soviet Atomic Energy, 24, 323-326 (Translated from Atomnaya Énergiya, 24, 265-267).

[16] Hunt, L.H. and Miller, W.W. (1965) Activation Analysis for Oxygen-18 Isotope Abundance Utilizing Recoil Protons. Analytical Chemistry, 37, 1269-1272. http://dx.doi.org/10.1021/ac60229a025

[17] Takahashi, M. and Iijima, S. (1989) Activation of Structural Materials Due to Recoil Protons in Light Water Reactor. Journal of Nuclear Science and Technology, 26, 874-880. http://dx.doi.org/10.1080/18811248.1989.9734399

[18] Kiefer, R.L. and Hillman, M. (1969) Relative Yields of ${ }^{58 \mathrm{~g}} \mathrm{Co},{ }^{58 \mathrm{~m}} \mathrm{Co}$, and ${ }^{56}$ Co Produced by Low-Energy Tritons. Journal of Inorganic and Nuclear Chemistry, 31, 915-917. http://dx.doi.org/10.1016/0022-1902(69)80137-5

[19] Mukhammedov, S., Khaidarov, A. and Barsukova, E.G. (2008) ${ }^{7}$ Be Yield Produced in Secondary Reactions in a Nuclear Reactor. Atomic Energy, 104, 82-84. http://dx.doi.org/10.1007/s10512-008-0012-z

[20] Mukhammedov, S., Khaidarov, A. and Akramov, F. (2012) Nuclear Reactions Induced by Secondary Protons Formed under the Influence of Fast Neutrons. International Conference "Nuclear Science and its Application", Samarkand, 25-28 September 2012, 338-339.

[21] Ortec (2003) GammaVision-32 Software User's Manual. 6th Edition, Printed in USA.

[22] Fornaciari Iljadica, M.C. and Cohen, I.M. (2008) The Production of ${ }^{7} \mathrm{Be}$ in a Nuclear Reactor. Book of Abstracts, NRC7-Seventh International Conference on Nuclear and Radiochemistry, Budapest, 24-29 August 2008, 54.

[23] Siri, S. and Cohen, I.M. (2008) The Triton-Induced Production of ${ }^{48} \mathrm{~V}$ in a Nuclear Reactor. Book of Abstracts, NRC77th International Conference on Nuclear and Radiochemistry, Budapest, 24-29 August 2008, 235.

[24] Siri, S. and Cohen, I.M. (2009) Production of ${ }^{48} \mathrm{~V}$ in a Nuclear Reactor via Secondary Tritons. Radiochimica Acta, 97, 543-546. http://dx.doi.org/10.1524/ract.2009.1676

[25] Fornaciari Iljadica, M.C., Siri, S., Alí Santoro, M.C. and Cohen, I.M. (2012) Las Reacciones Secundarias Inducidas sobre Hierro por Tritones y Protones de Retroceso en Reactores Nucleares. Abstracts, XXIX Argentine Conference of Chemistry, “Centenary of the Argentine Chemical Association”, Mar del Plata, 23. http://aqa.org.ar/pdf99/cd/Qca\%20Inorganica,\%20Bio,\%20radio.nucl/23.pdf

[26] Siri, S. and Cohen, I.M. Unpublished Results.

[27] Siri, S., Fornaciari Iljadica, M.C. and Cohen, I.M. (2012) La Producción de ${ }^{74}$ As en Reactores Nucleares. Abstracts, XXIX Argentine Conference of Chemistry, “Centenary of the Argentine Chemical Association”, Mar del Plata, 20. http://aqa.org.ar/pdf99/cd/Qca\%20Inorganica,\%20Bio,\%20radio.nucl/20.pdf 
Scientific Research Publishing (SCIRP) is one of the largest Open Access journal publishers. It is currently publishing more than 200 open access, online, peer-reviewed journals covering a wide range of academic disciplines. SCIRP serves the worldwide academic communities and contributes to the progress and application of science with its publication.

Other selected journals from SCIRP are listed as below. Submit your manuscript to us via either submit@scirp.org or Online Submission Portal.
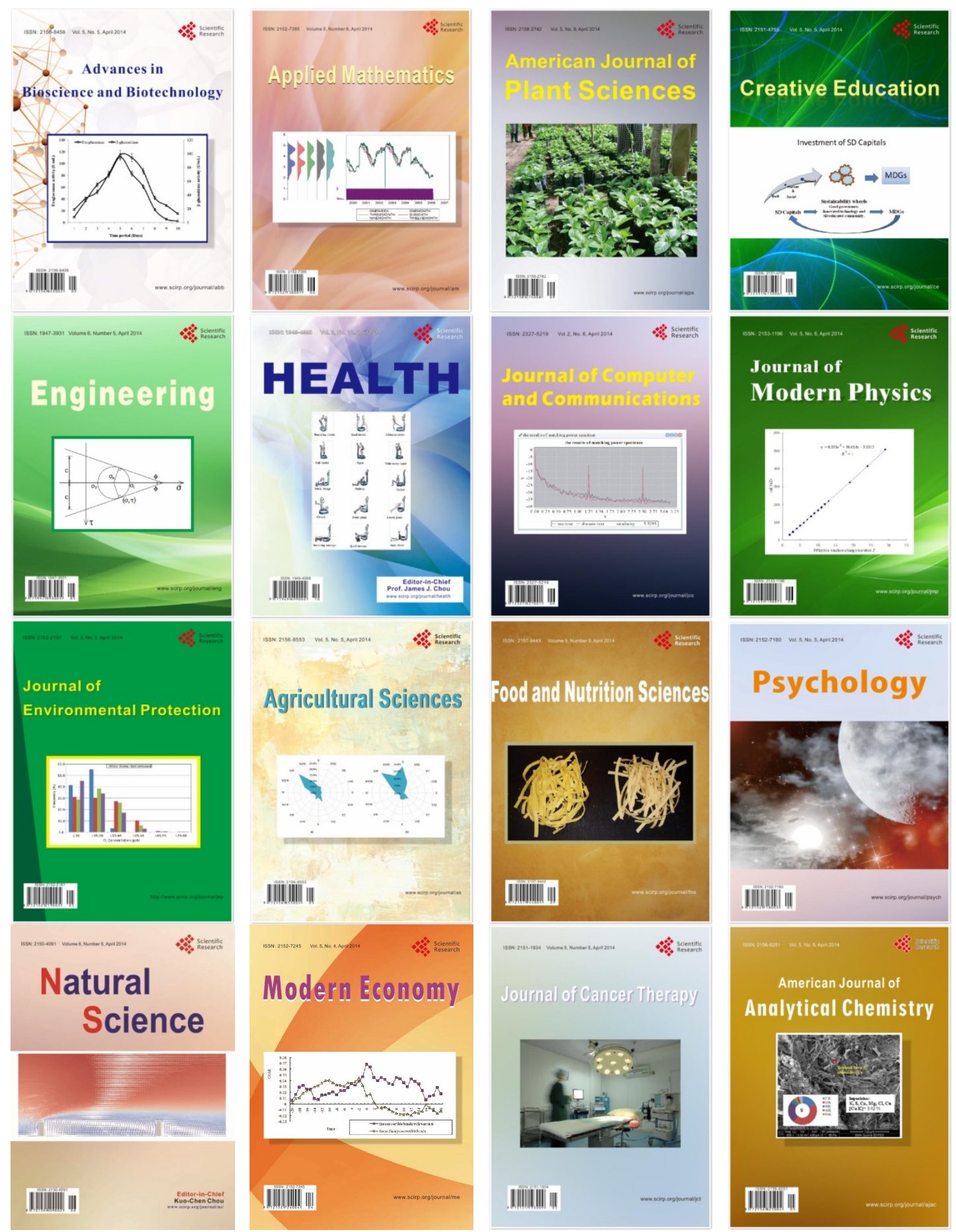